Gordon Wood MD, Brian Milne MD FRCP, Victor Spjeda MD FRCP, Jlee Lewis MD

\title{
Ventilatory failure due to an improperly placed nasogastric tube
}

\begin{abstract}
A case is described of a 35-yr-old patient who was transferred to the operating room for the repair of a right ventricular laceration. Prior to transfer a nasogastric tube was placed unknowingly beyond the tracheal tube cuff into the trachea. During the surgery, the patient's head was turned to insert a central venous line at which time the ventilator low pressure alarm sounded and effective ventilation ceased. The problem was corrected by turning off the nasogastric tube suction. It is posiulated that the nasogastric tube became unkinked when the head was turned and this led to the evacuation of gas from the lungs and breathing circuit through the nasogastric tube suction. Identification of the problem was complicated by the lack of a temporal relationship between the insertion and connection to suction of the nasogastric tube, and the episode of ventilatory failure.
\end{abstract}

Un cas d' un patient de 35 ans est décrit lors d' une réparation de lacération du ventricule droit en salle d'opération. Avant le transfert un tube nasogastrique fut placé par inadvertance dans la trachée à travers le ballonnet du tube endotrachéal. Lors de l'opération, la tête du patient fut tournée afin d'insérer un cathéter veineux central et c' est à ce moment-là que l'alarme de basse pression du ventilateur fut déclenchée détectant une ventilation inefficace. Le problème fut corrigé en cessant la succion par le tube nasogastrique. On postule que le tube nasogastrique fut désobstrué quand la tête fut tournée et ceci amena l'évacuation des gaz et des poumons et dans le circuit par la succion à travers le tube nasogastrique. L'identification du problème fut compliquée par le manque de relation temporelle entre l'insertion et la connection du tube nasogastrique à la succion et l'épisode d'absence de ventilation.

\section{Key words}

EQUIPMENT: gastric tube;

VENTILATION: failure.

From the Department of Anaesthesia, Kingston General Hospital, Queen's University, Kingston, Ontario.

Address correspondence to: Dr. G. Wood, Department of Anacsthesia, Kingston General Hospital, Stuart Strcet, Kingston, Ontario K7L 2V7.

\section{Case report}

A $35 \mathrm{yr}$-old $80 \mathrm{~kg}$ man was transferred from an adjacent hospital with two knife wounds to the right chest. There, in the Emergency Department, his trachea was intubated and an emergency thoracotomy performed. He was found to have a laceration in the right ventricle and pericardial tamponade. The tamponade was relieved and the bleeding from the right ventricle was controlled with manual compression. A nasogastric tube was inserted to relieve gastric distention. Once haemodynamic variables were stable, the patient was transfered to our hospital where the cardiothoracic service was located. He was given pancuronium $10 \mathrm{mg}$ and incremental doses of fentanyl for the short transfer.

He arrived in our operating room with a heart rate of 120 beats $\cdot \mathrm{min}^{-1}$ and systolic blood pressure of 60 $\mathrm{mmHg}$. The lungs were ventilated with 100 per cent oxygen through a Bain circuit with a fresh gas flow of 10 $\mathrm{L} \cdot \mathrm{min}^{-1}$. The nasogastric tube was attached to wall suction and anaesthesia was maintained with a total of $2000 \mu \mathrm{g}$ of fentanyl. Resuscitation was continued with $\mathrm{O}$ negative blood while the surgeons repaired the right ventricle. Once the patient's blood pressure had stabilized, preparations were made to insert a central venous line. The patient's head was turned to the left to expose the right side of the neck. At this point the ventilator's low-pressure alarm sounded. Direct inspection of the lungs showed that they were not being ventilated. No disconnection was found in the breathing system and there was no gas leak around the tracheal tube cuff. The pipeline and cylinder pressure gauges for $\mathrm{O}_{2}$ and $\mathrm{N}_{2} \mathrm{O}$ indicated normal pressures, and the $\mathrm{O}_{2}$ flow meter continued to read $10 \mathrm{~L} \cdot \mathrm{min}^{-1}$. The bellows on the Ohio V5 (descending bellows) ventilator were deflated and remained contracted at the top of the rigid pressure chamber. The ventilator was disconnected and a reservoir bag was attached to the circuit. The bag did not fill with gas and remained contracted. It was determined that negative pressure was being applied to the breathing circuit. The suction to the nasogastric tube was turned off and the breathing bag quickly filled with gas allowing the patient to again be ventilated. Inspection of the patient's oropharynx showed that the nasogastric tube was coiled 
once in the mouth before going through the larynx into the trachea and past the low-pressure cuff of the tracheal tube.

The problem was quickly identified and corrected and the patient's oxygen saturation did not decrease during the period when there was no ventilation. After surgery there was no clinical or radiological evidence of pulmonary oedema or atelectasis to indicate significant pulmonary damage from the negative pressure applied to the lungs. The hole in the right ventricle was closed and the patient recovered uneventfully.

\section{Discussion}

A previous case report has described an incident when, after the induction of anaesthesia and the institution of positive pressure ventilation, a nasogastric tube was inadvertently passed through a low-pressure tracheal cuff into the trachea and connected to suction. ' This led to an immediate loss of ventilator function as in the case described above. In the previously reported case the authors recommend that "when something goes wrong immediately after making a change, first consider the change as the source of the problem." What was unique to our case was that the nasogastric tube was placed outside the operating room and despite being connected to suction, for the first $30 \mathrm{~min}$ of the procedure, there was no ventilatory malfunction. The precipitating event was not the passage of the nasogastric tube or its connection to suction, but a change in the patient's head position. Presumably the nasogastric tube was kinked where it had been coiled in the mouth and thus despite being connected to suction, no problems had occurred initially. Turning the head laterally to insert a central line had probably unkinked the nasogastric tube allowing suction to be applied to the airway distal to the tracheal tube cuff. This depleted the breathing system of gas which prevented ventilation and activated the low-pressure alarm.

A delay in diagnosis and correction of this problem can lead to hypoventilation. Previously reported cases from intensive care units have described situations where nasogastric tubes in the trachea have led to patients receiving less than the set tidal volume. ${ }^{2,3} \mathrm{~A}$ proportion of the tidal volume was sucked out through the nasogastric tube and the patients were inadequately ventilated. In our case the suction was able to remove more than the fresh gas flow of $10 \mathrm{~L} \cdot \mathrm{min}^{-1}$ so there was immediate and total failure of ventilation. High subatmospheric pressures delivered to the lungs may also cause barotrauma. The suction was set at $200 \mathrm{mmHg}$ negative pressure and such pressures may lead to pulmonary oedema or atelectasis. ${ }^{4,5}$

Identification of the problem was complicated by the lack of a temporal relationship between the passage of the nasogastric tube and the ventilatory failure. The type of ventilator used helped in the diagnosis of the problem.
With an ascending bellows ventilator a circuit leak or application of negative pressure to the circuit both result in collapse of the bellows without an indication of the specific problem. A descending bellows ventilator, as was used in this case, will remain expanded if there is a disconnect or leak whereas the bellows will collapse with suction. In the case described the bellows was seen to be contracted at the top of the rigid pressure chamber of the ventilator during the episode of ventilation failure. This indicated that negative pressure was being applied to the breathing circuit. Once suction was identified as the cause of the problem the source was easily found and the problem corrected. The only other likely source of subatmospheric pressure in the breathing circuit in a paralyzed patient would be from a faulty active scavenging system. ${ }^{6}$

Activation of the low-pressure alarm is most often due to a disconnect, a major leak in the breathing system, or a failure of gas supply. ${ }^{6}$ If these problems are excluded the possibility that the nasogastric tube is in the trachea should be considered.

This case emphasizes the need to determine the proper positioning of a nasogastric tube both after insertion and when receiving a patient with one in place. Complications may also be avoided by connecting the nasogastric tube to high negative pressure wall suction only when specifically indicated and not as a routine.

In summary, a case of ventilatory failure secondary to a malpositioned nasogastric tube is described. One should be aware that a patient may be transferred to the operating room with a nasogastric tube placed in the trachea without any obvious signs such as a cuff leak. Serious complications may occur some time later making identification of the cause of the problem difficult.

\section{References}

1 Stirt JA, Lewenstein $L N$. Circle system failure induced by gastric suction. Anaesth Intensive Care 1981; 9 : 161-2.

$2 Z$ wagill $L W$, Metzeroff $K O$. Mcchanical ventilation compromised by misplacement of nasogastric tube. Respiratory Care 1973; 18: 60-1.

3 Sweatman AJ, Tomasello PA, Loughhead MG, Orr M. Dutta $T$. Misplacement of nasogastric tubes and oesophageal monitoring devices. Br J Anacsth 1978; 50: 389-92.

4 Schnelle $N$, Nelson $D$. A ncw device collecting and disposing of exhaust gases from the anesthesia machine. Anesth Analg 1969; 48: 744-7.

5 Conway $C M$. Haemodynamic effects of pulmonary ventilation. Br J Anaesth 1975; 32: 486-7.

6 Dorsch JA, Dorsch SE. Understanding Anesthesia Equipment. Baltimore: Williams and Wilkins, 1984; 156-7. 